\title{
Prosocial Modeling Matters: The Association Between Parent and Faculty Involvement in Fighting COVID-19 With Medical Students' Career Commitment
}

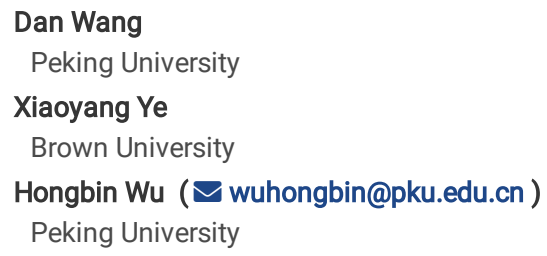




\section{Abstract}

Background: Role models play an important role in enhancing students' intention to pursue medical careers. While, as the two most influential role models for medical students, there is limited research to explore the different impacts between faculty and parents. This study investigated the association of different role model's prosocial behavior of joining the fight against novel coronavirus disease 2019 (COVID-19) on medical students' career commitment. We examined whether there are different effects and how these effects differ among different medical students.

Method: A national-scale survey was conducted with 118,030 undergraduate students majoring in clinical medicine in mainland China. Questions were asked to collect information of participants in the battle of COVID-19, medical students' determination of practicing medicine after graduation, as well as students' socio-demographic characteristics. Chi-square tests and hierarchical regressions were performed to examine the effects of parent and faculty involvement on students' career commitment.

Results: The results showed that prosocial modeling during the COVID-19 pandemic in China is associated with students' intention to pursue medical careers. The effect of faculty was greater than that of parents on medical students. Gender was related to the effects. And those who already determined to be the doctor before the pandemic were much more likely to persist in the medical profession.

Conclusions: Our study provides more definitive answers to the issue of who has a greater effect on medical students' career commitment between parents and faculty. Encouraging faculty to act as positive role models could help medical students increase the intention to become doctors.

\section{Introduction}

The shortage of healthcare workers is a worldwide problem. The World Health Organization (WHO) and the Association of American Medical Colleges (AAMC) have both published reports to emphasize the shortage of healthcare workers [1, 2]. The concern is more expanded by a high attrition rate (about $15 \%$ in China each year) among medical students [3], which leads to a significant loss of the accumulated human capital in medicine. While prosocial modeling can be an important teaching strategy for encouraging medical students to commit to their careers. In late January 2020, the novel coronavirus disease 2019 (COVID-19) was first reported in Wuhan, the capital of Hubei province in China. It has since spread rapidly across the world. As the medical resources in Hubei, the epicenter of COVID-19, were insufficient to deal with the outbreak, tens of thousands of medical staff from all over China came to the province's aid. More than 20,000 of these staff were from hospitals affiliated with medical colleges [4]. Numerous non-healthcare workers (particularly government officials and social workers) also actively participated in the fight against COVID-19. Like in other countries, this nationwide prosocial behavior received widespread praise and respect.

Medical students who are exposed to parents' and faculty's frontline involvement in the fight against COVID-19 are likely to be affected by this behavior. This study presents the first empirical evidence of the association between this emerging prosocial behavior with medical students' intention to pursue medical careers. We focused on the frontline involvement of the parent and faculty in fighting COVID-19 as a type of prosocial behavior by using a nationally representative sample of undergraduate medical students in China $(N=99,559)$. We identified the different effects of the parent and faculty as prosocial modeling on the students' commitment to their careers by comparing students with different levels of exposure to parental and faculty involvement in the fight against COVID-19.

\section{Prosocial modeling}

Prosocial behavior is a type of action that benefits or promotes others or groups [5]. And it is a direct product of social learning [6]. Modeling plays an important role in the form of prosocial behavior [7]. Prosocial modeling was used to foster prosocial behavior. And it could be a strategy used in educational institutions [8]. One of the mechanisms of prosocial modeling is goal contagion, which means they share the same goal. A study reported that observer may adopt the underlying prosocial goal and achieve them in another way [9]. Highly prosocial medical workers have been found to have high levels of professional commitment [10]. Would prosocial behavior increase the commitment of medical students to their careers? The outcome of this prosocial behavior remains obscure. Some research reported a positive impact of prosocial modeling on prosocial behavior of individuals [11, 12]. Some studies stated no effect or negative effect $[13,14]$. The factors that may affect prosocial modeling effect include cultural values, modeling medium, and model's reinforcement contingencies [9]. Little is known about the connection between the behavior of the individual and their relationship with prosocial modeling.

\section{Parent modeling}

Parents, who are typically role models for their children, have meaningfully influence on their offspring[15]. A study of 520 high school students showed that teenagers' plans for the future can be influenced by their parents as role models [16]. Teenagers' views on their parents' jobs can affect their career plans. The occupations of parents can therefore significantly affect their children's career choices. Parents are central to children's socialization and achievement-related behaviors and their motivations for these behaviors. Parents influence their children's choices mainly through their wishes, values, and beliefs, in addition to their positions and social relationships [17]. The intention of medical students to pursue medical careers can thus be influenced by their parents. A survey conducted in 2014 in Germany showed that nearly half of the surveyed medical school applicants had family members with medical backgrounds; in most cases, their parents were physicians [18]. Some of the students directly indicated that relatives who had practiced medicine had led them to develop similar interests during childhood [19].

\section{Faculty modeling}

Parents play an important role in determining the environments in which children grow up. However, as children learn skills and enter society as adults, other role models, such as faculty members for students, can become influential. Faculty role models have been found to be important in medical education. Their 
significance to the professional development of medical students has been confirmed by medical educators worldwide [20-23]. A positive role model can have an impact on medical students' 1) progress through the medical profession; 2) development of professional identity; and 3) choice of career [24]. Medical students may seek to emulate role models' passion for their careers [25]. Many studies have confirmed the influence of parents and faculty on the intention of medical students to become doctors, but empirical evidence of the different influences of parents and faculty is lacking.

Previous studies have, however, indicated that these influences may differ. Parents of preschool children and school-teachers were assessed as role models in terms of the children's healthy lifestyles, and the results showed that the parents but not school-teachers had a more significant impact [26]. Studies of adolescent students have demonstrated that they are more likely to leave their parents and seek help from teachers [27]. In the process of becoming doctors, medical students can be viewed as in "Communities of Practice" (CoP) with faculty members [28]. CoP was proposed by Lave and Wenger in 1991 [29]. And it is widely used in medical education [30]. The definition which seems appropriate for medicine was develop by Barab: "a continuous social network of individuals who share and develop an overlapping knowledge base, beliefs, values, and experiences aimed at a common practice" [31]. The crucial elements of community of practice are mutual engagement, a joint enterprise and shared repertoire [32]. The concept of CoP is clear that medical students, as a novice member, moves from legitimate peripheral participation to the full community $[29,33]$. Participation of medical students with member of the community is important. As it allowed medical students to recreate meaning and identity [32,34]. Medical students learn how to be mature doctors through the process of communicating with faculty, and thus look up to faculty members.

What's more, there are differences among medical students. Research has shown that gender is a key factor affecting career choice [35]. Students from different learning phases have a different extent of interaction with their faculty. And the relationship with their faculty would have an impact on their career choice [36]. During the pandemic of COVID-19, the influence of different regions is different. Would it affect medical students' career commitment?

We therefore, asked the following three research questions. (1) Would the prosocial behavior of role models during the COVID-19 outbreak associated with the commitment of medical students to their careers? (2) Does the effect of the parental role model differ from that of the faculty role model? (3) Do the observed effects depend on the students' specific characteristics?

\section{Method}

\section{Participants and Survey}

A national scale, multi-site survey was conducted in China with the support of the National Centre for Health Professionals Education Development. According to the location, type and reputation of the medical schools, we sampled 90 institutions of China's 181 medical schools. Between February 21 and March 14 , 2020, when the epidemic in Hubei Province was basically under control, we distributed the questionnaire to students of these medical schools (total undergraduate medical students enrolled: $\mathrm{N}=225,329)$ via the professional version of the online survey platform WJX (https://www.wjx.cn/). University administrators invited the students to voluntarily participate in the survey and no sensitive questions were asked. The responses were anonymous, but each survey was unique to each participant, and it could not be shared or completed more than once.

\section{Dependent variable}

The survey item "The pandemic has made me more committed to my future career as a doctor" was used to assess whether the pandemic increased the intention of the students to pursue medical careers. Using a 5-point Likert scale, we classified those who reported "strongly agree" (5) or "agree" (4) as having an increased intention to become doctors.

\section{Independent variables}

We used two questions to measure parent and faculty involvement in the COVID-19 outbreak. The question "Does either of your parents serve on the frontline against COVID-19?" was used to measure parental involvement, with three possible responses: "both parents," "one parent," or "neither parent." We combined options 1 and 2 to indicate parental involvement (the results were similar when we examined the two items separately). The question "Have your faculty members gone to Hubei province to take part in the battle against COVID-19?" was used to measure faculty involvement, with the two choices of "yes" or "no." Additionally, we asked the question "Are either of your parents doctors?" to examine whether there are parents in the medical profession. The options were "both parents," "one parent," or "no." We combined 1 and 2 to indicate that the respondents had one or two doctors as parents. We then divided the medical students into four groups. Those in group 1 knew no-one who had gone to Hubei province to assist in the battle against COVID-19; Group 2 only knew faculty members who had participated; Group 3 consisted of those whose parents had gone to Hubei; And those in group 4 both had parents and knew faculty who had participated in the battle against COVID-19. Each group was then divided into two types according to whether their parents were doctors or not.

\section{Control variables}

We also considered other control variables, including gender, self-reported academic performance (top 25\%, 25\%-50\%, 50\%-75\%, bottom 25\%), learning phase, home location (urban or rural), the region of the medical schools, and whether the students had planned to become doctors before the pandemic. The learning phases were divided into four phases according to the clinical medical training phases [37]. The regions in which the medical schools were located were separated into three, according to the classification of the National Health Commission of the People's Republic of China [38].

\section{Statistical analysis}

We first established summary descriptive statistics of the variables. Chi-square tests were used to examine the relationships between types of role models and the intention of medical students to become doctors. Logistic models in which hierarchical regression were applied to estimate the effects. Parental involvement and faculty involvement in the battle against COVID-19 were included in the model as the first step. The students' willingness to become doctors before the pandemic was included as the second step. The third step including characteristics of the students such as their gender, home location, academic

Page $3 / 10$ 
performance, the region of their college, and their learning phase. Finally, to explore the heterogeneous effects, we chose the four variables of prior career commitment, gender, learning phase, and region. We estimated the effects of parental and faculty involvement separately by using these moderating variables. The significance level was set to 0.05. All analyses were performed using Stata SE15.

\section{Results}

\section{Summary statistics}

In total, 118,030 medical students responded to the survey (with a response rate of $62.38 \%$ ), and the final sample consisted of 99,559 valid responses. The characteristics of the study participants are summarized in Table 1. This study included 60,815 (61.08\%) female and 38,744 (38.92\%) male students. More students attended the eastern and central than the western schools, which conforms to the general proportions of students at Chinese medical schools. Before the COVID-19 outbreak, 85,922 of the students (86.30\%) wanted to become doctors after graduation and 13,637 (13.70\%) did not.

Table 1

Summary statistics for medical students in the study $(n=99,559)$

\begin{tabular}{|ll|}
\hline Variables & $\mathbf{N}(\%)$ \\
\hline Gender & \\
\hline Female & $60,815(61.08)$ \\
\hline Male & $38,744(38.92)$ \\
\hline Academic performance & \\
\hline Bottom 25\% & $6,320(6.35)$ \\
\hline $50 \%-75 \%$ & $21,112(21.20)$ \\
\hline $25 \%-50 \%$ & $35,687(35.85)$ \\
\hline Top 25\% & $36,440(36.60)$ \\
\hline Region & \\
\hline Eastern & $38,134(38.30)$ \\
\hline Central & $41,341(41.53)$ \\
\hline Western & $20,084(20.17)$ \\
\hline Area (home location) & \\
\hline Rural & $13,637(13.70)$ \\
\hline Urban & $45,922(86.30)$ \\
\hline Learning phase & $30,869(31.00)$ \\
\hline General education & $10,890(10.94)$ \\
\hline Basic medical education & $58,021(58.28)$ \\
\hline Clinical medical education & \\
\hline Clerkship rotation & \\
\hline Willingness to become a doctor before the pandemic & \\
\hline No & \\
\hline Yes & \\
\hline
\end{tabular}

\section{Chi-square test results}

To understand the relationship between prosocial modeling and the increased intention of medical students to become doctors, we compared the parent and faculty involvement groups, as shown in Table 2. A total of $66.47 \%(\mathrm{~N}=66,180)$ students had an acquaintance (either a parent or a faculty member) who had assisted in the fight against the COVID-19 outbreak. Of these, 47,940 (72.44\%) expressed a greater intention to pursue a medical career after the pandemic. Among students without such acquaintances, 22,930 (68.70\%) expressed the same intention. The chi-square test results revealed a statistically significant difference in the intention to pursue a medical career between the two groups $(p<0.001)$.

To further examine the different effects of parents and faculty members as prosocial role models, we grouped the medical students according to their acquaintances and their parents' occupations, and then conducted the chi-square tests. The results showed a statistically significant difference between these groups whether parents are doctors or not $(p<0.001)$. The details are given in Table 2 . 
Table 2

The relationship between role models and medical students' intention to become doctors

\begin{tabular}{|c|c|c|c|}
\hline & \multicolumn{2}{|c|}{$\begin{array}{l}\text { The COVID-19 pandemic has enhanced my commitment to be a } \\
\text { doctor }\end{array}$} & \multirow[t]{3}{*}{$\begin{array}{l}\text { Chi- } \\
\text { square }\end{array}$} \\
\hline & No $n=28,689(\%)$ & Yes n = 70,870 (\%) & \\
\hline & $(28.82)$ & (71.18) & \\
\hline $\begin{array}{l}\text { Have an acquaintance who has participated in anti-pandemic } \\
\text { activities }\end{array}$ & & & $151.5^{\star \star \star}$ \\
\hline No & $10,449(31.30)$ & $22,930(68.70)$ & \\
\hline Yes & $18,240(27.56)$ & $47,940(72.44)$ & \\
\hline Parents are doctors & & & $30.2^{\star \star \star}$ \\
\hline Neither+ & 814(33.18) & $1,639(66.82)$ & \\
\hline Faculty & $1,103(27.71)$ & 2,877(72.29) & \\
\hline Parents & 298(30.28) & $686(69.72)$ & \\
\hline Both faculty and parents & $752(27.00)$ & 2,033(73.00) & \\
\hline Parents are not doctors & & & $137.6^{\star \star \star}$ \\
\hline Neither+ & $9,635(31.16)$ & $21,291(68.84)$ & \\
\hline Faculty & $15,281(27.61)$ & $40,058(72.39)$ & \\
\hline Parents & 233(29.05) & $569(70.95)$ & \\
\hline Both faculty and parents & $573(25.02)$ & $1,717(74.98)$ & \\
\hline
\end{tabular}

\section{Hierarchical regression results}

Table 3 provides the results of the hierarchical regression. According to step 3 , We found that the increased intention to pursue a medical career was lower for students whose parents were doctors $(\mathrm{OR}=0.864, p<0.01)$. The participation of faculty significantly associated with increased commitment of medical students to pursuing future medical practice (Faculty and doctor parents: $\mathrm{OR}=1.236, p<0.001$; Faculty and non-doctor parents: $\mathrm{OR}=1.165, p<0.001$ ), while parent participation played no significant role (Parents and doctor parents: $\mathrm{OR}=0.970, p=0.687$; parents and non-doctor parents: $\mathrm{OR}=1.093, p=0.286$ ). After controlling for other factors, when the students' parents were doctors and the students were acquainted with faculty who had participated in the fight against the COVID-19, their intention to become doctors were higher than that of the students in the control group (whose parents were not doctors and who lacked acquaintances). However, no significant difference was found in the intentions of the students whose parents had participated in the pandemic compared with the control group, whether their parents were doctors or not.

The students' intention to become doctors before the pandemic had a significant effect on their subsequent intentions to become doctors. The students who wanted to become doctors before the pandemic were five times more committed than those who did not (Wanted to become a doctor before the pandemic: $\mathrm{OR}=5.397, p<0.001)$. Also, the results revealed that the male students had a greater intention to practice medicine than the female students $(\mathrm{Male}$ : OR $=$ $1.060, p<0.001)$. Those with better grades were also more inclined to become doctors. The increased intention to pursue a medical career was higher for those from the central region than those from the eastern region, followed by those from the western region. As the higher the learning stage, the lower the increased intention. 
Table 3

Hierarchical regression results $(n=99,559)$

Variables

Participation (base: neither \& parents are not doctors)

Neither \& Parents doctors

Faculty \& Parents doctors

Faculty \& Parents not doctors

Parents \& Parents doctors

Parents \& Parents not doctors

Both \& Parents doctors

Both \& Parents not doctors

Key independent variable

Wanted to become a doctor before the pandemic

Demographics

Male

Urban

Academic performance (base: bottom 25\%)

$50 \%-75 \%$

$25 \%-50 \%$

Top $25 \%$

Region (base: eastern)

Central

Western

Step 1

Step 2

Step 3

$0.911^{*}$

$1.186^{\star \star *}$

$1.180 * * *$

1.042

1.105

$1.223^{\star \star *}$

$1.356^{\star \star \star}$

$1.324 * \star \star$

$5.465^{\star \star \star}$

$5.397 * \star \star$

$1.060 * \star$

0.989

$1.191^{\star \star *}$

$1.341^{\star * \star}$

$1.535^{\star \star \star}$

1.171

0.967

Learning phase (base: general education)

Basic medical education

$0.852^{\star \star *}$

Clinical medical education

$0.622^{\star * *}$

Clerkship rotation

$0.528 * \star \star$

"Neither" means that neither parents nor faculty was involved in efforts to combat the pandemic. " $\&$ " indicates that two conditions are met at the same time. For example, "Faculty \& parents are doctors" means that faculty participated in the pandemic and the parents are also doctors. Robust standard errors are clustered at the college level. ${ }^{* *} p<0.001,{ }^{* \star} p<0.01,{ }^{*} p<0.05$

\section{Heterogeneity}

We applied logistic models with hierarchical regression with four variables, which were prior career commitment, gender, learning phase, and region of the institution. Each logistic model was used to explore the association between parents' and faculty's participation in the fight against COVID-19 with medical students' intention to become doctors. The results are shown in Table 4 . We only report the odd ratio values of the participation of faculty and the parent when the parents were doctors.

For those students who have prior career commitment, the participation of faculty was significantly associated with the medical career commitment (OR $=$ $1.219, p<0.001)$, while the association of parents' participation with medical career commitment was not significant $(O R=1.015, p=0.858)$. For male students, the participation of faculty was related to the medical career commitment (Male \& Faculty: OR $=1.323, p<0.001$ ), but the result of the participation of parent was not (Male \& Faculty: $O R=0.955, p=0.625$ ). For those students who have entered the rotation period of clinical practice, the participation of faculty was significantly associated with the medical career commitment at the $10 \%$ level (Clerkship rotation \& Faculty: OR $=1.333, p=0.061$ ), while the participation of parent not. The outcomes concerning regions were of interest. For students studying in the eastern and central regions, the participation of faculty showed significantly association with the higher intention to pursue medicine as a career, while the participation of parent did not. (Eastern \& Faculty: $O R=1.183, p<0.01$; Central \& Faculty: $O R=1.133, p<0.05$ ). For students studying in the western regions, neither the participation of faculty nor parent have significant impact on medical students' career commitment. 
Table 4

Comparison of the faculty participation and parents participation when parents are doctors $(n=4,964)$

\begin{tabular}{|c|c|c|}
\hline Variables & Faculty's participation & Parents' participation \\
\hline \multicolumn{3}{|l|}{ Prior career commitment } \\
\hline Did not want to become a doctor & 0.894 & 0.733 \\
\hline Wanted to become a doctor & 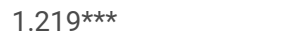 & 1.015 \\
\hline \multicolumn{3}{|l|}{ Gender } \\
\hline Female & 1.052 & 0.991 \\
\hline Male & $1.323^{\star \star \star}$ & 0.955 \\
\hline \multicolumn{3}{|l|}{ Learning phase } \\
\hline General education & 1.199 & 1.304 \\
\hline Basic medical education & 1.108 & 0.880 \\
\hline Clinical medical education & 1.132 & 0.896 \\
\hline Clerkship rotation & 1.333 & 1.430 \\
\hline \multicolumn{3}{|l|}{ Region } \\
\hline Eastern & $1.183^{*}$ & 1.015 \\
\hline Central & $1.133^{\star}$ & 0.897 \\
\hline Western & 1.213 & 1.049 \\
\hline \multicolumn{3}{|c|}{$\begin{array}{l}\text { Each row represents a logistic model. We only show the OR values of the participation of parents and faculty when the medical students' parents were } \\
\text { doctors. The logistic model: medical students' intention }=\log (x i \mid \mathrm{V}=1) \text {, xi includes group, whether students wanted to be doctors before the pandemic, } \\
\text { gender, academic performance, learning phase, home location, and region of college. } V \text { is the value of the variables. For example, if } v=\text { female, OR (Facult } \\
\text { \& parents doctors })=1.052 \text {, OR (Parents \& parents doctors })=0.991 \text {. Robust standard errors are clustered at the college level. }\end{array}$} \\
\hline \multicolumn{3}{|l|}{$\star \star \star ~ p<0.001, * \star p<0.01, * p<0.05$} \\
\hline
\end{tabular}

\section{Discussion}

In this study, we analyzed a large-scale, nationally representative sample of 99,559 students from 90 medical schools in China. We illustrated the association between prosocial behavior of role models with medical students' intention to pursue a medical career. We found that faculty's prosocial behavior had a greater effect than parents on the medical students. This study contributes to the understanding of the effects on medical students of exposure to role models' frontline involvement in the fight against COVID-19.

Existing studies have shown that prosocial modeling promote prosocial behavior. In one case, children who watched a cartoon about helping puppies were more likely to help others than those who had not watched the cartoon [39]. Another study showed that after observing an example of active blood donation, the probability that college students would donate blood was higher than that of students without the blood donation model [40]. Our study is based on the assumption that the doctor can offer a role model to medical students, and confirms the positive effect that the prosocial behavior of role models participating in the battle against the pandemic can have.

We found that during the COVID-19 pandemic, prosocial modeling has associated with medical students' intention to pursue a medical career, and that the effect of faculty on medical students was greater than that of the students' parents. Studies of adolescent students have demonstrated that they are more likely to leave their parents and seek help from teachers [27]. From the perspective of the theory of the CoP, medical students are in a common community of learning/practice with their faculty. They share the same ideas, and their occupational expectations are influenced most by other members of the community. Medical students join this community as novices and obtain knowledge and skills, along with the identity conferred by their membership of the community [28]. They share the same goal of preventing and treating human diseases [41]. Medical students learn from faculty members what it is to be a doctor [42], and they may retain the faculty's behavior, which then affects their motivations and occupational expectations. The role of parents is perhaps reflected more in the choice of medical major [18]. Students are familiar with their parents but not necessarily with faculty. Thus, by combining the familiar and unfamiliar into one group, the influence of faculty could have been underestimated. This again highlights the power wielded by faculty as role models [24, 43], which is greater than the influence of family at this stage of learning. Doctors should be aware of the effect of role models, and that by being good role models they can attempt to avoid negative effects on medical students.

The willingness to become a doctor before the pandemic is significantly associated with medical students' commitment. Students who wanted to become doctors before the pandemic, compared with those who did not, demonstrated a greater increase in the intention to pursue the medical career. Factors that can influence the career choices of medical students include the potentially high income, their status as perceived by their colleagues, and opportunities to benefit their families [44, 45]. Altruistic and scientific reasons have been found to be the main motivations for medical students' career choices [46], but the primary motivation can differ between countries and depend on the level of income [47]. 
We found that during the COVID-19 pandemic, male students were more affected by role models than female students. A survey conducted in Japan found that women prefer disciplines such as pediatrics, gynecology, obstetrics, and psychology, while men prefer orthopedics and operating, suggesting that medical students of different gender have different motivations [48]. A controllable lifestyle has been found to be an important factor in women's choices [35], and women have been shown to attach more importance to family and lifestyle than men [49]. The social definition of the male role is often as more independent, with a stronger sense of social responsibility. Masculine traits such as strength and tenacity can also be viewed as attracting especial respect [50]. Thus, men may be more encouraged than women by others' involvement in the fight against the pandemic and become more determined to pursue medical careers.

Those majoring in clinical medicine in China typically go through four phases. The first is general education, in which the main courses are chemistry, mathematics, sociology, biology, computer science, and English. The second phase is basic medical education, which includes anatomy, histology and embryology, biochemistry, and physiology. The third phase is clinical medical education, which includes basic clinical courses such as internal medicine, surgery, obstetrics, gynecology, pediatrics, and diagnostics. The fourth phase is that of clerkship rotation, in which students' study with the clinical faculty of various departments in a hospital [37]. Some studies have shown that before entering medical college, the mental health levels of medical students are the same or higher than those of their peers [51, 52], but after starting medical school their mental health can deteriorate [53-55]. Senior students are particularly likely to suffer from burnout $[54,56,57]$, which is related to the level of stress they experience. Good support can, however, reduce the possibility of burnout [58], and good communication with faculty can have a positive impact on students' learning perceptions [36]. Our research suggests that faculty might have a positive effect on the intention of medical students to pursue a medical career when in the clerkship rotation phase, while parents do not. The rotation phase is when medical students have the closest contact with faculty, and it is also the key phase in which medical students imitate their role models. The experiences of medical students in the clinical phase thus significantly affect their choices, and so the positive guidance of faculty is extremely important. Our research confirms this. Although the pandemic affects the arrangement of rotation, students of this learning phase may be more sensitive than others.

We found a statistically significant association between the region and the increased intention to pursue medicine as a career. The central region, as the epicenter of the pandemic, was most sensitive to it, and thus the anti-pandemic behavior of medical staff in the central region was more extensive. Thus, the prosocial behavior of role models was more apparent. According to figures released by the National Health Commission of the PRC, the eastern region sent the most medical personnel of all regions of China [59]. Half of the medical staff participating in anti-pandemic work were from affiliated hospitals of the university, and thus typically taught medical students as faculty. The more local medical faculty were involved in the fight against COVID-19, the greater students intended to become doctors. For the eastern and central regions, faculty played a significant role in increasing the students' intention to practice medicine, while the parent group did not. This indicates that the prosocial behavior of faculty plays a greater role than that of parents in medical students' intention to pursue a medical career in these regions. This is also consistent with our hypothesis.

This study has several limitations. First, we only measured the influence of parents in general, without distinguishing between the influences of fathers and mothers on their offspring. Some studies have reported that the influences of fathers and mothers on children differ [60]. Second, this study was conducted during the pandemic, so we did not consider the effects of the key variables on medical students after the pandemic. It is unclear how long the effect may last. Finally, this survey was self-reported, and thus may have included reporting and selection bias. We intend to address these limitations in the future.

\section{Conclusion}

We analyzed completed questionnaires from 99,559 medical students from 90 medical schools in China. Our findings found that during the COVID-19 pandemic, the prosocial behavior of role models had a positive association with medical students' intention to pursue medical career, and that faculty role model had a greater effect than parental role model. Those who have prior medical career commitment are much more likely to persist in the medical profession and prosocial modelling of faculty are associated with their medical career commitment. This suggests that the professional identity of students should be strengthened throughout their training. And encouraging faculty to act as positive role models could help medical students increase their career commitment.

\section{Declarations}

\section{Ethics approval and consent to participate}

The authors participated training from Peking University Institutional Review Board (PKU IRB) and got the certificate. PKU IRB usually exempts educational research from the requirement of ethical approval. This study was granted an exemption from requiring ethics approval by the PKU IRB because the survey was anonymous and did not include sensitive questions. An introduction about the survey was provided on the first page of the questionnaire, including aims, the main contents of this survey and promise to keep the data anonymous and confidential. Informed consent was obtained from all students. And the sampled students had the right to withdraw at any time. We confirm that all methods were carried out in accordance with relevant guidelines and regulations.

\section{Consent for publication}

Not applicable

\section{Availability of data and materials}

The datasets used and analyzed during the current study are available from the corresponding author on reasonable request.

\section{Competing interests}

None 


\section{Funding}

Supported by National Natural Science Foundation of China for Young Scholars, and the program number is 71804005

\section{Authors' contributions}

DW performed the data analysis, and wrote the manuscript. XY helped with the data analysis and the manuscript preparation. HW designed the questionnaire and modified the manuscript.

\section{Acknowledgements}

The authors wish to thank all participants who completed the questionnaire and are much indebted to the Ministry of Education (MOE) of the People's Republic of China for helping with the implementation of this survey.

\section{References}

1. AAMC. The Complexities of Physician Supply and Demand: Projections from 2018-2033. 2020. https://www.aamc.org/datareports/workforce/data/complexities-physician-supply-and-demand-projections-2018-2033. Accessed 11 Jan 2021.

2. World Health Organization. The World Health Report 2006: working together for health. 2006. 19(3):385-387.

3. Lien SS, Kosik RO, Fan AP, Huang L, Zhao X, Chang X, Wang Y, Chen Q: 10-year trends in the production and attrition of Chinese medical graduates: an analysis of nationwide data. LANCET 2016; 388:s11

4. Xinhua. Seven things China has done right to battle coronavirus. http://en.nhc.gov.cn/2020-03/14/c_77719.htm. Accessed 23 Jun 2020.

5. Batson, C. D., \& Powell, A. A. Altruism and Prosocial Behavior. New Jersey (NJ): John Wiley \& Sons. 2003.

6. Chudek M, Henrich J: Culture-gene coevolution, norm-psychology and the emergence of human prosociality. Trends Cogn Sci. 2011; 15(5):218-226.

7. House BR, Kanngiesser P, Barrett HC, Broesch T, Cebioglu S, Crittenden AN, Erut A, Lew-Levy S, Sebastian-Enesco C, Smith AM et al: Universal norm psychology leads to societal diversity in prosocial behaviour and development. Nat Hum Behav. 2019; 4(1):36-44.

8. Spivak, A, \& Durlak, J. 2016. School Intervention and Prosocial Behaviour. Encyclopedia on Early Childhood development. https://www.researchgate.net/profile/Asha_Spivak/publication/292964250_School_Intervention_and_Prosocial_Behaviour/links/56b2438e08ae795dd5c; Accessed 11 Jan 2021.

9. Jung H, Seo E, Han E, Henderson MD, Patall EA: Prosocial modeling: A meta-analytic review and synthesis. Psychol Bull. 2020; 146(8):635-663.

10. Joana FBO, John MTT, Rachel FCV, Chiu JL: Impact of Quality Work Life and Prosocial Motivation on the Organizational Commitment and Turnover Intent of Public Health Practitioners. Rev Integr Busi and Econ Res. 2019; 8:24-43.

11. Doescher SM, Sugawara Al: Impact of Prosocial Home- and School-Based Interventions on Preschool Children's Cooperative Behavior. Fam Relat. 1992;41(2):200-204.

12. Poulos RW, Liebert RM: Influence of modeling, exhortative verbalization, and surveillance on children's sharing. Dev Psychol. 1972;6(3):402-408.

13. Effron DA, Conway P: When virtue leads to villainy: advances in research on moral self-licensing. Curr Opin Psychol. 2015; 6:32-35.

14. White GM: Immediate and deferred effects of model observation and guided and unguided rehearsal on donating and stealing. J Pers Soc Psychol. 1972;21(2):139-148.

15. Ferrinho P, Valdes AC, Cabral J: The experience of medical training and expectations regarding future medical practice of medical students in the Cubansupported Medical School in Timor-Leste. Hum Resour Health. 2015; 13(1):13.

16. Wiese BS, Freund AM: Parents as role models: Parental behavior affects adolescents' plans for work involvement. Int J Behav Dev. 2011;35(3):218-224.

17. Eccles JS, Wigfield A: Motivational Beliefs, Values and Goals. Annu Rev Psychol. 2002; 53(1):109-132.

18. Simmenroth-Nayda A, Görlich Y: Medical school admission test: advantages for students whose parents are medical doctors? BMC Med Educ. 2015;15(23):81.

19. Woodward A, Thomas S, Jalloh MB, Rees J, Leather A: Reasons to pursue a career in medicine: a qualitative study in Sierra Leone. Glob Health Res and Policy. 2017; 4(2):34.

20. Hamiltoncraig C: As others see us: students' role models in medicine. Med J Aust. 1998; 169(8):103-105.

21. Wright S, Wong A, Newill C: The Impact of Role Models on Medical Students. J Gen Intern Med. 1997; 12(1):53-56.

22. Yazigi A, Nasr M, Sleilaty G, Nemr E: Clinical teachers as role models: Perceptions of interns and residents in a Lebanese medical school. Med Educ. 2006;40(7):654-661.

23. Gordon JJ, Lyon PM: As others see us: students' role models in medicine. Med J Aust.1998; 169(2):103-105.

24. Passi V, Johnson N: The impact of positive doctor role modeling. Med Teach. 2016; 38(11):1139-1145.

25. Burgess A, Goulston K, Oates K: Role modelling of clinical tutors: a focus group study among medical students. BMC Med Educ. 2015; 15(1).

26. Natale RA, Messiah SE, Asfour L, Uhlhorn SB, Delamater A, Arheart KL: Role modeling as an early childhood obesity prevention strategy: effect of parents and teachers on preschool children's healthy lifestyle habits. J Dev Behav Pediatr. 2014; 35(6):378-387.

27. Wang M, Eccles JS: Social Support Matters: Longitudinal Effects of Social Support on Three Dimensions of School Engagement From Middle to High School. Child Dev. 2012; 83(3):877-895. 
28. Cruess RL, Cruess SR, Steinert Y: Medicine as a Community of Practice. Acad Med. 2018; 93(2):185-191.

29. Lave J, Wenger E: Situated learning: legitimate peripheral participation. Cambridge [England]: Cambridge University Press; 1991.

30. Cantillon P, D Eath M, De Grave W, Dornan T: How do clinicians become teachers? A communities of practice perspective. Adv in Health Sci Educ. 2016; 21(5):991-1008.

31. Barab SA, Barnett M, Squire K: Developing an Empirical Account of a Community of Practice: Characterizing the Essential Tensions. J LEARN SCI. 2002; 11(4):489-542.

32. Wenger E: Communities of practice: learning, meaning, and identity. New York; Cambridge, U.K: Cambridge University Press; 1998.

33. Director FP, Ferguson E: Understanding Medical Education: Evidence, Theory and Practice; New Jersey (NJ): Wiley-Blackwell.2010.

34. Cruess RL, Cruess SR, Boudreau JD, Snell L, Steinert Y: Reframing Medical Education to Support Professional Identity Formation. Acad Med. 2014; 89(11). 35. Lee CW: Gender Difference and Specialty Preference in Medical Career Choice. Korean J Med Educ. 2013; 25(1):15-21.

36. Schut S, van Tartwijk J, Driessen E, van der Vleuten C, Heeneman S: Understanding the influence of teacher-learner relationships on learners'assessment perception. Adv in Health Sci Educ. 2020, 25(2):441-456.

37. Schwarz MR, Wojtczak A, Zhou T: Medical education in China's leading medical schools. Med Teach. 2004; 26(3):215-222.

38. NHC. China Health Statistics Yearbook 2013, 2013. http://www.nhc.gov.cn/htmlfiles/zwgkzt/ptjnj/year2013/2010t1.files/01.htm. Accessed 11 Jan 2021.

39. Sprafkin JN, Liebert RM, Poulos RW: Effects of a prosocial televised example on children's helping. J Exp Child Psychol. 1975; 20(1):119-126.

40. Rushton JP, Campbell AC: Modeling, vicarious reinforcement and extraversion on blood donating in adults: Immediate and long-term effects. Eur J Soc Psychol. 1977; 7(3):297-306.

41. Pellegrino ED: The medical profession as a moral community. Bull NY Acad Med. 1990; 66(3):221-232.

42. Althouse LA, Stritter FT, Steiner BD: Attitudes and Approaches of Influential Role Models in Clinical Education. Adv in Health Sci Educ. 1999; 4(2):111-122.

43. Vimmi, Passi, Samantha, Johnson, Ed, Peile, Scott, Wright, Fred, Hafferty: Doctor role modelling in medical education: BEME Guide No. 27. Med Teach. 2013;35(9):e1422-1436.

44. Osborn HA, Glicksman JT, Brandt MG, Doyle PC, Fung K: Primary care specialty career choice among Canadian medical students: Understanding the factors that influence their decisions. Can Fam Physician. 2017; 63(2):e107-e113.

45. Querido S, van den Broek S, de Rond M, Wigersma L, Ten Cate O: Factors affecting senior medical students' career choice. Int J Med Educ. 2018; 9:332339.

46. Gąsiorowski J, Rudowicz E, Safranow K: Motivation towards medical career choice and future career plans of Polish medical students. Adv in Health Sci Educ. 2015; 20(3):709-725.

47. Goel S, Angeli F, Dhirar N, Singla N, Ruwaard D: What motivates medical students to select medical studies: a systematic literature review. BMC Med Educ. 2018; 18(1):10-16.

48. Kawamoto R, Ninomiya D, Kasai Y, Kusunoki T, Ohtsuka N, Kumagi T, Abe M: Gender difference in preference of specialty as a career choice among Japanese medical students. BMC Med Educ. 2016; 16(1):288

49. Sanfey HA, Saalwachter-Schulman AR, Nyhof-Young JM, Eidelson B, Mann BD: Influences on Medical Student Career Choice: Gender or Generation? Arch Surg. 2006; 141(11):1086-1094, 1094.

50. Morris EW: Bridging the Gap: 'Doing Gender', 'Hegemonic Masculinity', and the Educational Troubles of Boys. Soc Compass. 2011; 5:92-103.

51. Brazeau CMLR, Shanafelt T, Durning SJ, Massie FS, Eacker A, Moutier C, Satele DV, Sloan JA, Dyrbye LN: Distress Among Matriculating Medical Students Relative to the General Population. Acad Med. 2014; 89(11):1520-1525.

52. Dyrbye LN, Thomas MR, Shanafelt TD: Systematic Review of Depression, Anxiety, and Other Indicators of Psychological Distress Among U.S. and Canadian Medical Students. Acad Med. 2006; 81(4):354-373.

53. Dahlin M, Joneborg N, Bo R: Stress and depression among medical students: a cross-sectional study. Med Educ. 2005; 39(6):594-604.

54. Dyrbye LN, Thomas MR, Huntington JL, Lawson KL, Novotny PJ, Sloan JA, Shanafelt TD: Personal Life Events and Medical Student Burnout: A Multicenter Study. Acad Med. 2006; 81(4):374-384.

55. Dyrbye LN, West CP, Satele D, Boone S, Tan L, Sloan J, Shanafelt TD: Burnout Among U.S. Medical Students, Residents, and Early Career Physicians Relative to the General U.S. Population. Acad Med. 2014; 89(3):443-451.

56. Paro HBMS, Silveira PSP, Perotta B, Gannam S, Enns SC, Giaxa RRB, Bonito RF, Martins MA, Tempski PZ, Hermes-Lima M: Empathy among Medical Students: Is There a Relation with Quality of Life and Burnout? PloS One. 2014; 9(4):e94133.

57. Bruce CT, Thomas PS, Yates DH: Burnout and psychiatric morbidity in new medical graduates. Med J Aust. 2005; 182(11):599.

58. Prins JT, Gazendam-Donofrio SM, Dillingh GS, Wiel HBMV, Hoekstra-Weebers JEHM: The relationship between reciprocity and burnout in Dutch medical residents. Med Educ. 2008; 42(7):721-728.

59. PRC: White clothing armor expeditio - National Health Commission of the PRC, http://www.nhc.gov.cn/wjw/mtbd/202003/e0d5f8a773b54fc39113988dbcb19136.shtml. Accessed 11 Jan 2021.

60. Guo J, Marsh HW, Parker PD, Dicke T, Van Zanden B: Countries, parental occupation, and girls' interest in science. Lancet. 2019; 393(10171):e6-e8. 